\title{
Synergistic effect of eugenol with Colistin against clinical isolated Colistin-resistant Escherichia coli strains
}

\author{
Yi-ming Wang, Ling-cong Kong, Jie Liu and Hong-xia Ma* (1)
}

\begin{abstract}
Background: Bacterial infections have become more challenging to treat due to the emergence of multidrugresistant pathogenic bacteria. Combined antibiotics prove to be a relatively effective method to control such resistant strains. This study aim to investigate synergistic activity of eugenol combined with colistin against a collection of clinical isolated Escherichia coli (E.coli) strains, and to evaluate potential interaction.

Methods: Antimicrobial susceptibility, minimum inhibitory concentration (MIC) and fractional inhibitory concentration index (FICl) of the bacteria were determined by disk diffusion assay, broth microdilution method and checkerboard assay, respectively. The mcr-1 mRNA expression was measured by Real-time PCR. To predict possible interactions between eugenol and MCR-1, molecular docking assay was taken.

Results: For total fourteen strains including eight colistin-resistant strains, eugenol was determined with MIC values of 4 to $8 \mu \mathrm{g} / \mathrm{mL}$. Checkerboard dilution test suggested that eugenol exhibited synergistic activity when combined with colistin ( $\mathrm{FICl}$ ranging from 0.375 to 0.625 ). Comparison analysis of Real-time PCR showed that synergy could significantly down-regulate expression of mcr-1 gene. A metal ion coordination bond with catalytic zinc atom and a hydrogen bond with crucial amino acid residue Ser284 of MCR-1 were observed after molecular docking, indicating antibacterial activity and direct molecular interactions of eugenol with MCR-1 protein.
\end{abstract}

Conclusions: Our results demonstrated that eugenol exhibited synergistic effect with colistin and enhanced its antimicrobial activity. This might further contribute to the antibacterial actions against colistin-resistant E.coli strains.

Keywords: eugenol, colistin-resistant Escherichia coli, mcr-1 gene, molecular docking

\section{Background}

The challenge presented by the emergence of antibiotic resistance is increasingly significant. Colistin, as an old member of polymycin group, has a better broad-spectrum activity against Gram-negative bacteria including most species of Enterobacteriaceae and is regarded as the last resort for treatment of multiple drug resistance (MDR). However, the currently emerged plasmid-mediated colistin resistance mechanism MCR-1 has already been reported, which has posed great threats to both human and animals [1-4]. Therefore, it is urgently needed to find effective combination therapy and antibiotic succedaneum to

\footnotetext{
* Correspondence: hongxia0731001@163.com

College of Animal Science and Technology, Jilin Agricultural University,

Xincheng Street No.2888, Changchun 130118, China
}

eradicate the colistin-resistant bacteria and to slow down its spread and prevalence.

Essential oils (EOs) are naturally derived from many plants with a series of pharmacological activities and have been widely used in traditional medicine and food preservation. Many studies have documented EOs to be effective antimicrobial against E. coli, $S$. aureus, Lactobacillus sp., Bacillus thermoacidurans, Salmonella sp. [5-9]. Moreover, the synergistic combinations with other EOs and conventional antimicrobials have also been widely reported since last decade [10-14]. Eugenol, a phenylpropanoid found in many plants and the major active essential oil component of clove, has been reported to have antioxidant properties, protective effect on the cardiovascular system, antibacterial and antifungal effect in previous studies. 
Several studies support that its antibacterial activity is closely related to the capability to permeabilize the cell membrane, destroy membrane integrity and facilitate the entry of eugenol into the cytoplasm which finally interacts with proteins and enzymes, and leads to the leakage of intracellular substances [10, 11, 15-17].

The current study aim to investigate the synergistic activity of eugenol combined with colistin against a collection of clinical E.coli isolates and to predict possible interactions between eugenol and MCR-1.

\section{Methods}

\section{Antimicrobial agents and culture medium}

Eugenol was obtained from Macklin Biochemical (Shanghai, China) Co.,Ltd. and was dissolved in MH broth. Dimethyl sulfoxide (DMSO, Sigma-Aldrich, USA) was added with a final concentration of $1 \%$. Triphenyltetrazolium chloride (TTC) was purchased from Biotopped Co., LTD (Beijing, China). Colistin was purchased from National Institutes for Food and Drug Control (Beijing, China). Mueller-Hinton broth (MHB) and Mueller-Hinton agar (MHA) were obtained from Qingdao Hope BioTechnology Co., LTD (Qingdao, China). Lysogeny broth (LB) from Sangon Biotech (Shanghai, China) Co., Ltd. Commercial antibiotic paper disks: AMP(Ampicillin,10 $\mu \mathrm{g})$, AZM(Azithromycin,15 $\mu \mathrm{g}), \quad$ CFZ(Cefazolin,30 $\mu \mathrm{g})$ ), CTX(Cefotaxime, $30 \mu \mathrm{g}$ ), DOX(Doxycycline,30 $\mu \mathrm{g}$ ), FF(Florfenicol,30 $\mu \mathrm{g}$ ), FRZ(furazolidone,300 $\mu \mathrm{g}$ ), GEN(gentamicin,10 $\mu \mathrm{g}), \mathrm{KAN}($ kanamycin,30 $\mu \mathrm{g}), \mathrm{LVX}($ levofloxacin, $5 \mu \mathrm{g})$, $\mathrm{NEO}($ Neomycin,30 $\mu \mathrm{g}$ ), NOR(Norfloxacin,10 $\mu \mathrm{g}$ ), POL(PolymyxinB,300 IU), STR(Streptomycin,10 $\mu \mathrm{g})$, TCY(Tetracycline,30 $\mu \mathrm{g}$ ) were purchased from Hangzhou Microbial Reagent Co.,Ltd. (Hangzhou, China).

\section{Preparation of the McFarland standard}

$0.5 \mathrm{ml}$ of $1.17 \% \mathrm{BaCl}_{2}(w / v)$ was added to $99.5 \mathrm{ml}$ of $0.18 \mathrm{M} \mathrm{H}_{2} \mathrm{SO}_{4}(1 \% \mathrm{v} / \mathrm{v})$ with constant stirring.

\section{Bacterial strains}

Thirteen clinical isolated E.coli strains were collected from duck $(n=1)$, peacock $(\mathrm{n}=1)$, bovine $(\mathrm{n}=1)$, fox ( $\mathrm{n}$ $=1)$, zebra $(n=1)$, porcine $(n=3)$, goose $(n=4)$ and avian $(\mathrm{n}=1)$. All porcine isolates, two goose isolates $(E$. coli Goose 3, E. coli Goose 4) and one bovine isolate were previously confirmed to be mcr-1 gene positive according to the PCR test. E.coli ATCC 25922 was employed in this study as quality control strains.

\section{Disk diffusion assay}

The drug resistance status of twelve clinical isolated $E$. coli strains was determined using agar disk diffusion method. Briefly, the inoculum was adjusted to 0.5 McFarland standards (equivalent to $10^{8} \mathrm{cfu} / \mathrm{ml}$ ). Steriled plates containing $\mathrm{MH}$ agar medium were seeded with
$100 \mu \mathrm{l}$ each bacterial strain. Fifteen kinds of commercial antibiotic paper disks were placed on the surface of the inoculated plates. Incubations were carried out for $16 \mathrm{~h}$ at $37^{\circ} \mathrm{C}$. Antibacterial susceptibility was determined by measuring the diameter of the inhibition zone (in $\mathrm{mm}$ ) generated around the disc according to the manufacturer's protocol. Discs of cefazolin were used as positive controls. All the tests were performed in triplicate.

\section{Determination of MIC}

The MIC was determined by broth microdilution method [18]. Bacterial colonies of each strain were cultured in LB broth at $37{ }^{\circ} \mathrm{C}$ to reach McFarland standards 0.5. The suspensions were further diluted to obtain an inoculum of $10^{6} \mathrm{cfu} / \mathrm{ml}$. The drugs, serial 2-fold diluted in $\mathrm{MHB}$, were inoculated with bacterial suspension to obtain a final concentration of $5 \times 10^{5} \mathrm{cfu} / \mathrm{ml}$. Then, TTC was added as growth indicator of less than $2 \%$ of the total test volume. All strains were determined antibiotics resistance according to MIC breakpoint of colistin (EUCAST, Version 7.1). MICs were defined as the lowest concentration of test samples that resulted in a complete inhibition of visible growth after incubation.

\section{Time-kill curves}

Time-kill methods were used to evaluate the antibacterial effects of eugenol against all E. coli strains by measuring the reduction in the number of $\mathrm{cfu} / \mathrm{mL}$ within $160 \mathrm{~min}$. Eugenol (corresponding to MIC)was incubated with equal volume $E$. coli strains. For control, MHB was added instead of eugenol. All samples were incubated at $37{ }^{\circ} \mathrm{C}$. After $0,20,40,80,120,160 \mathrm{~min}$ of incubation, $100 \mu \mathrm{l}$ samples were removed, 10-fold diluted and spread on the surface of MHA for colony counting. Each assay was performed in triplicate.

\section{Checkerboard assay}

The combined antibacterial effects of eugenol with colistin were assessed by checkerboard test as previously described [19]. Briefly, both eugenol and colistin were diluted to make seven gradient concentrations: from 1/16 MIC to 2 MIC. Each longitudinal column tubes containing same concentration of drug $\mathrm{A}$, and each horizontal row of tubes containing same concentration of drug B. Each tube was inoculated with bacterial suspension to make a final concentration of approximately $5 \times 10^{5} \mathrm{CFU} / \mathrm{ml}$. Moreover, single drug control tubes, colistin-free control tubes, eugenol-free control tubes and blank control tubes were also set. E. coli ATCC 25922 was used as sensitivity control strain. All tubes were incubated at $37{ }^{\circ} \mathrm{C}$ for $16 \mathrm{~h}$ under aerobic conditions. The experiment was repeated in triplicate. MIC values obtained for a given combination were used to evaluate the effects of 
combination between eugenol and colistin by calculating the FICI using formula: FICI = MIC of eugenol in combination/MIC of eugenol alone; FIC of colistin = MIC of colistin in combination/MIC of colistin alone. "Synergy" was defined when $\mathrm{FICI} \leq 0.5 ; 0.5<\mathrm{FICI} \leq 0.75$ means "partial synergy"; $0.76<\mathrm{FICI} \leq 1$ denotes "additive"; $1<\mathrm{FICI} \leq 4$ denotes "indifferent"; while "antagonistic" in cases which the FIC index $>4$. In this study, synergy and partial synergy were defined as synergy relationship, while additive, indifferent and antagonistic were regarded as non-synergy.

\section{Real-time PCR}

Expression of mcr-1 gene at mRNA level was also evaluated using Real-time PCR. Bacteria was cultured to logarithmic phase, eugenol was then mixed with bacteria to make a final concentration of sub-MIC (1/4 MIC). While in control group, $\mathrm{MH}$ broth was added instead of eugenol. The mixture was incubated at $37{ }^{\circ} \mathrm{C}$ and shaking at $160 \mathrm{rpm}$ for $16 \mathrm{~h}$. Total RNA was extracted using RNAiso Plus (TaKaRa) and was then reverse transcribed to cDNA using PrimeScript ${ }^{\mathrm{m}} \mathrm{RT}$ reagent Kit (TaKaRa). The extracted RNA was adjusted the same concentration during DNA elimination process before reverse transcription.

Real-time PCR was carried out in an Applied Biosystems 7500 Real-Time PCR System (USA). The primers were retrieved and designed according to E. coli strain SHP45 plasmid pHNSHP45 complete sequence (GenBank accession no. KP347127.1). The amplifications were performed in $20 \mu \mathrm{l}$ reaction mixtures containing $10 \mu \mathrm{l}$ mastermix with SYBR ${ }^{\circ}$ Green I, $0.4 \mu \mathrm{l}$ ROX Reference Dye II(SYBR Premix Ex Taq II, Tli RNaseH Plus, Code No.RR820A/B, Takara), $0.8 \mu \mathrm{lmcr}-1$ forward and reverse primer $(10 \mu \mathrm{M})$, $6.0 \mu \mathrm{l}$ double distilled $\mathrm{H}_{2} \mathrm{O}$, respectively, and $2.0 \mu \mathrm{l}$ template were added to each reaction sample. 16SrRNA of the strain was used as a reference gene (Table 1).

The reacting condition was set as two steps method as follows: pre-denaturation at $95^{\circ} \mathrm{C}$ for 30 s, 40 cycles consisting of denaturation at $95^{\circ} \mathrm{C}$ for $5 \mathrm{~s}$, annealing at $60^{\circ}$ $\mathrm{C}$ for $34 \mathrm{~s}$. All templates were run in triplicate.

\section{Molecular docking}

To study the possible interaction between eugenol and MCR-1, molecular docking was performed via AutoDock Vina software. Crystal structure of MCR-1 (PDB ID: 5GRR), available at Protein Data Bank was obtained in

Table 1 Sequences of primers used in this study

\begin{tabular}{llc}
\hline Primer name & Sequence(5'-3') & Product size(bp) \\
\hline mcr-1-F & TGCTCCAAAATGCCCTACAGACC & 141 \\
mcr-1-R & TGCCCCAAGTCGGATAATCCAC & \\
16SrRNA-F & TGTCGTCAGCTCGTGTTGTG & 130 \\
16SrRNA-R & ATCCCCACCTTCCTCCAGTT & \\
\hline
\end{tabular}

PDB format. Weighting parameters of scoring function include spatial interaction, hydrophobic interaction, hydrogen-bonding energy and number of rotatable keys in ligand. Affinity was measured to assess docking. The lower the parameter is, the ligand is more likely to bind with the active pocket. PyMol molecular graphics system was used for analysis of their modes of interaction with binding site residues.

\section{Statistical analysis}

Data were expressed as mean \pm standard deviation. Statistical significance was analyzed by one-way analysis of variance (ANOVA) using SPSS 17.0 software. In all comparisons, $P<0.01$ or $P<0.05$ was considered statistically significant.

\section{Results}

\section{Antimicrobial susceptibility test}

According to the obtained results, the thirteen clinical $E$. coli isolates were resistant to selected antibiotics to varying degrees. Details of drug resistance status are shown in Tables 2 and 3, which clearly demonstrated that all isolates were multi-drug resistant E. coli.

\section{Time-kill analysis of eugenol}

Based on the results of MIC assay, the time-kill curve was used to describe the viability after treated with eugenol. As shown in Fig. 1, although at MIC, eugenol exhibited a bactericidal effect on most $E$. coli strains within $120 \mathrm{~min}$. In contrast, eugenol only inhibited the growth of E. coli Goose 2, E. coli Peacock and E. coli Avian rather than inactivation. Similarly, the MIC value often met the $\mathrm{MBC}$ value in our previous study, which indicated that eugenol may act as a bactericidal agent. The above results suggested that eugenol exerted a strong and rapid antibacterial effect on E. coli.

\section{Synergistic effect of eugenol with colistin}

Eugenol was evaluated for its antimicrobial activity against thirteen clinical isolated E. coli strains and one sensitivity control strain. The results of the antimicrobial activity showed that eugenol presented almost identical antimicrobial activity against all tested strains (MIC, 4 to $8 \mu \mathrm{g} / \mathrm{mL}$ ). As shown in Table 4, for E. coli isolates E. coli Porcine 2 and $E$. coli Zebra, the combination of eugenol and colistin exerted strong synergistic effect, where the addition of eugenol at 1/4MIC concentrations resulted in 8-fold MIC reduction of colistin ( $\mathrm{FICI}=0.375$, respectively). For ATCC 25922, E. coli Porcine 3, E. coli Goose 1, E. coli Goose 2, E. coli Goose 3 and E. coli Avian, 4-fold MIC reduction of colistin was observed after combined with $1 / 4 \mathrm{MIC}$ eugenol $(\mathrm{FICI}=0.5)$. For $E$. coli Porcine 1, E. coli Duck, E. coli Goose 4, E. coli Peacock, E. coli Fox and E. coli Bovine, the addition of $1 / 4$ 
Table 2 Antimicrobial resistance profile of clinical Escherichia coli isolates

\begin{tabular}{lll}
\hline Strains & Isolates used & Antimicrobial resistance $^{\text {a }}$ \\
\hline E. coli Porcine1 & colistin-resistant & STR, TCY \\
E. coli Porcine2 & colistin-resistant & AMP, FF, GEN, KAN, TCY \\
E. coli Porcine3 & colistin-resistant & AMP, CFZ, CTX, FF, GEN, KAN, LVX, STR, NEO, NOR, TCY \\
E. coli Duck & colistin-sensitive & AMP, DOX, FRZ, KAN, STR, TCY \\
E. coli Goose1 & colistin-sensitive & AMP, DOX, FRZ, GEN, KAN, LVX, STR, NEO, NOR, TCY \\
E. coli Goose2 & colistin-resistant & AMP, AZM, DOX, FRZ, TCY \\
E. coli Goose3 & colistin-resistant & AMP, CFZ, DOX, FRZ, LVX, NOR, STR, TCY \\
E. coli Goose4 & colistin-resistant & AMP, AZM, DOX, FRZ, GEN, KAN, LVX, NOR, STR, NEO, TCY \\
E. coli Peacock & colistin-sensitive & AMP, AZM, DOX, GEN, LVX, NOR,STR, TCY \\
E. coli Zebra & colistin-sensitive & AMP, AZM, CFZ, CTX, DOX, FF, LVX, NOR,STR, TCY \\
E. coli Fox & colistin- resistant & AMP, AZM, CFZ, DOX, FRZ, GEN, LVX, NOR, STR, NEO, TCY \\
E. coli Bovine & colistin- resistant & AMP, FRZ, KAN, STR \\
E. coli Avian & colistin-sensitive & AMP, FRZ, GEN, KAN, STR \\
\hline
\end{tabular}

${ }^{a}$ The strain is resistant to the antibiotics

to $1 / 2$ MIC eugenol could partially synergize with colistin and resulted in 2 to 8 -fold MIC reduction (FICI $=0.625$ ).

\section{Analysis of real-time PCR}

To investigate if the synergy of eugenol with colistin has an effect on drug resistant gene at mRNA level, relative expression of mcr-1 were compared between synergy group and non-synergy group. Referring to the results presented in Fig. 2, significant differences of mcr-1 gene relative expression can be seen among synergy group and non-synergy groups, which clearly indicating that colistin resistance gene mor-1 was down-regulated by additional eugenol. Therefore, we speculate that eugenol might exhibits a direct inhibiting effect on drug resistant gene.

\section{Docking study of eugenol and MCR-1}

Referring to the results presented in Fig. 3, optimal interaction and relative affinity parameters were used to elucidate the spatial conformation among the MCR-1 protein and bioactive group of eugenol after docking. The results showed that free energy of binding was $10.087 \mathrm{kcal} / \mathrm{mol}$, which indicating a possible bind between MCR-1 protein and eugenol. A total of 24 ligand (eugenol) atoms could dock with MCR-1, and 2 among them were flexible. Hydrogen bonding (Hbond), important in determining the structure and function of a

Table 3 MIC of antibiotics against Escherichia coli strains MIC

\begin{tabular}{llllllllllllll}
\hline Antibiotics & AMP & AZM & CFZ & CTX & DOX & FF & GEN & KAN & LVX & NEO & NOR & STR & TCY \\
Strains & & & & & & & & & & & & \\
\hline ATCC 25922 & 4 & 8 & 1 & $<1$ & 2 & 2 & $<1$ & 2 & 0.5 & 4 & 1 & 8 & 1 \\
E.coli Porcine1 & 16 & 8 & 2 & $<1$ & 4 & 4 & 16 & 16 & 2 & 4 & 4 & 64 & 16 \\
E.coli Porcine2 & 128 & 8 & 4 & $\leq 1$ & 4 & 8 & 128 & 128 & 2 & 8 & 4 & 64 & 16 \\
E.coli Porcine3 & 256 & 8 & 4 & 16 & 8 & $>8$ & 128 & 256 & 16 & $>64$ & 32 & 64 & 32 \\
E. coli Duck & 128 & 8 & 4 & $<1$ & 32 & 2 & 32 & 64 & 2 & 8 & 4 & 128 & 64 \\
E.coli Goose1 & $>256$ & 16 & 4 & $\leq 1$ & 128 & 8 & 256 & 32 & 16 & $>64$ & 32 & 128 & 256 \\
E.coli Goose2 & 32 & 8 & 4 & $<1$ & 32 & 4 & 128 & 128 & 2 & 8 & 4 & 64 & 128 \\
E.coli Goose3 & $>256$ & 8 & 16 & 1 & 128 & 8 & 256 & 256 & 64 & 64 & $>64$ & 128 & 256 \\
E.coli Goose4 & $>256$ & 32 & 4 & 1 & 128 & $>8$ & 64 & 512 & 32 & $>64$ & 64 & 128 & 256 \\
E.coli Peacock & $>256$ & 8 & 4 & 1 & $>256$ & 8 & 256 & 512 & 32 & 8 & $>64$ & 256 & $>512$ \\
E. coli Zebra & 16 & 8 & $>32$ & $>32$ & 32 & 8 & 128 & 32 & 8 & 8 & 16 & 256 & 128 \\
E. coli Fox & $>256$ & 32 & 32 & 1 & $>256$ & $>8$ & 128 & 32 & 32 & $>64$ & $>64$ & 64 & $>512$ \\
E. coli Bovine & 16 & 8 & 2 & $<1$ & 4 & 2 & 32 & 32 & 2 & 8 & 4 & 32 & 4 \\
E. coli Avian & $>256$ & 8 & 2 & $<1$ & 16 & 2 & 128 & 32 & 2 & 8 & 4 & 64 & 16 \\
\hline
\end{tabular}




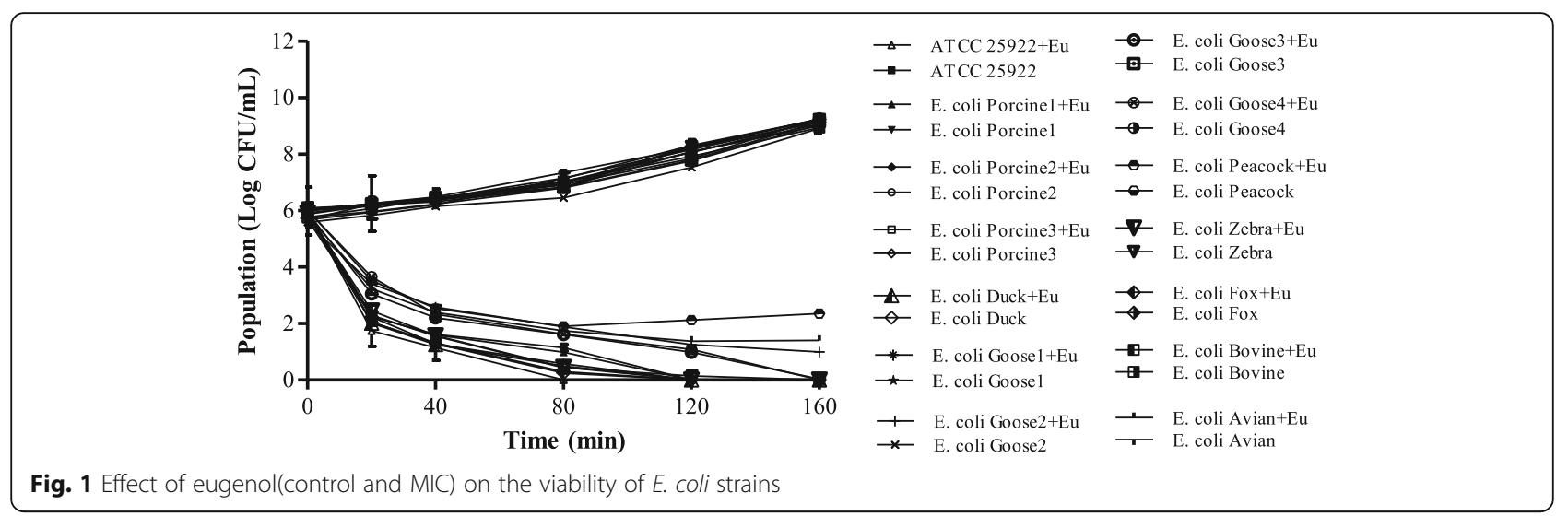

Table $4 \mathrm{MIC}$ and $\mathrm{FICl}$ of eugenol and colistin against Escherichia coli strains

\begin{tabular}{|c|c|c|c|c|c|}
\hline \multirow[t]{2}{*}{ Strains } & \multirow[t]{2}{*}{ Agents } & \multicolumn{2}{|c|}{$\mathrm{MIC}(\mu \mathrm{g} / \mathrm{mL})$} & \multirow[t]{2}{*}{$\mathrm{FICl}$} & \multirow[t]{2}{*}{ Outcome } \\
\hline & & Alone & Combination & & \\
\hline \multirow[t]{2}{*}{ ATCC 25922} & Eugenol & 4 & 1 & 0.5 & Synergy \\
\hline & Colistin & 1 & 0.25 & & \\
\hline \multirow[t]{2}{*}{ E. coli Porcine 1} & Eugenol & 4 & 2 & 0.625 & partial synergy \\
\hline & Colistin & 8 & 2 & & \\
\hline \multirow[t]{2}{*}{ E. coli Porcine2 } & Eugenol & 4 & 1 & 0.375 & Synergy \\
\hline & Colistin & 8 & 1 & & \\
\hline \multirow[t]{2}{*}{ E. coli Porcine3 } & Eugenol & 4 & 1 & 0.5 & Synergy \\
\hline & Colistin & 8 & 2 & & \\
\hline \multirow[t]{2}{*}{ E. coli Duck } & Eugenol & 4 & 2 & 0.625 & partial synergy \\
\hline & Colistin & 2 & 0.25 & & \\
\hline \multirow[t]{2}{*}{ E. coli Goose1 } & Eugenol & 4 & 1 & 0.5 & Synergy \\
\hline & Colistin & 2 & 0.5 & & \\
\hline \multirow[t]{2}{*}{ E. coli Goose2 } & Eugenol & 4 & 1 & 0.5 & Synergy \\
\hline & Colistin & 4 & 1 & & \\
\hline \multirow[t]{2}{*}{ E. coli Goose3 } & Eugenol & 4 & 1 & 0.5 & Synergy \\
\hline & Colistin & 4 & 1 & & \\
\hline \multirow[t]{2}{*}{ E. coli Goose4 } & Eugenol & 4 & 2 & 0.625 & partial synergy \\
\hline & Colistin & 16 & 2 & & \\
\hline \multirow[t]{2}{*}{ E. coli Peacock } & Eugenol & 8 & 4 & 0.625 & partial synergy \\
\hline & Colistin & 2 & 0.25 & & \\
\hline \multirow[t]{2}{*}{ E. coli Zebra } & Eugenol & 4 & 1 & 0.375 & Synergy \\
\hline & Colistin & 2 & 0.25 & & \\
\hline \multirow[t]{2}{*}{ E. coli Fox } & Eugenol & 4 & 1 & 0.625 & partial synergy \\
\hline & Colistin & 4 & 1 & & \\
\hline \multirow[t]{2}{*}{ E. coli Bovine } & Eugenol & 4 & 2 & 0.625 & partial synergy \\
\hline & Colistin & 16 & 2 & & \\
\hline \multirow[t]{2}{*}{ E. coli Avian } & Eugenol & 8 & 2 & 0.5 & Synergy \\
\hline & Colistin & 2 & 0.5 & & \\
\hline
\end{tabular}

biological molecule, possessed a score of -2.07393 . A metal ion coordination bond ( $2.1 \AA$ length) between phenolic hydroxyl group in eugenol and zinc atom was observed. Moreover, methoxy in ortho-position could bind with Ser284 in the form of hydrogen bond with a distance of $1.9 \AA$.

\section{Discussion}

The emergence of MDR bacterial strains appear to be the major cause of animal bacterial disease and have made commonly used therapy invalid, which have caused great economic loss and also posed great threats to human and animal health. Polymyxins consist of polymyxins $\mathrm{A}$ to $\mathrm{E}$, of which polymyxin $\mathrm{B}$ and polymyxin $\mathrm{E}$ (colistin) are commonly used in clinical mainly against the Gram-negatives [20]. The class of polymyxins is considered as the last option against MDR that are resistant to other currently available antibiotics [21]. Recently, Liu et al. reported a novel colistin- resistance gene (mcr-1) was located on the plasmid in Enterobacteriaceae isolated from food-producing animals, retail meat, and humans in China [1]. The gene showed a high transfer rate between $E$. coli strains during conjugation experiments in vitro. Moreover, mcr-2, a variant of mcr-1 and sharing $76.7 \%$ nucleotide identity, was revealed soon after the discovery of the paradigm gene mcr-1, which further highlight the prevalence and dissemination of mor-1 worldwide [22]. MCR-1 is regarded as a phosphoethanolamine transferase via sequence alignment and a member belonging to YhjW/YjdB/YijP superfamily. MCR-1 homologues LptA and EptC can catalyze modification of the $1^{\prime}$ and 4 ' phosphoryl groups of lipid $\mathrm{A}$ (moiety of lipopolysaccharides) using phosphoethanolamine (PEA) as a substrate to transfer positive charges, which will hinder the interaction and reduce affinity of colistin to lipid A therefore confers colistin resistance to host bacteria [23-25]. Concerning the urgent situation, to search for alternatives to substitute antibiotics and 

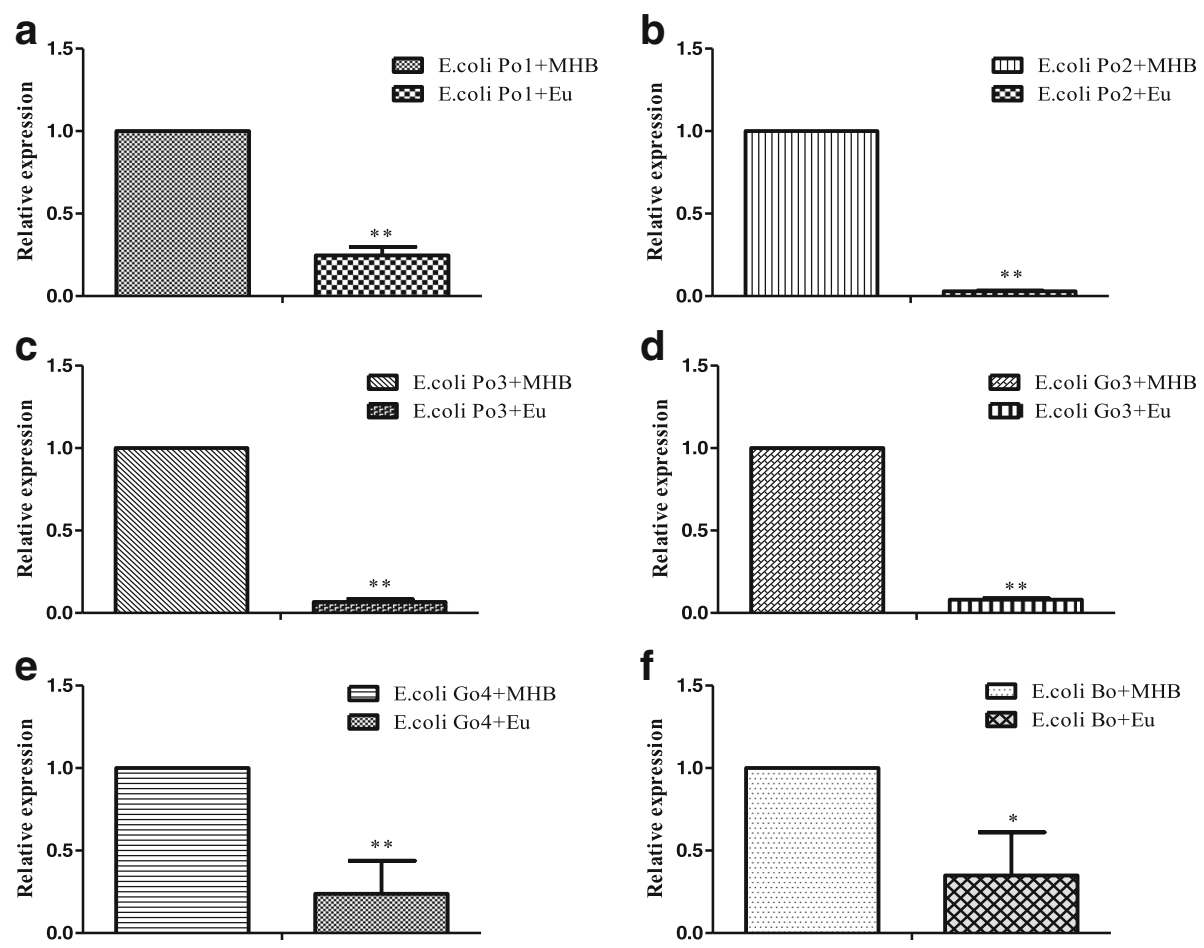

Fig. 2 Relative expression of mcr-1 gene. E. coli Po1 + MHB, E. coli Po1 + Eugenol (a), E. coli Po2 + MHB, E. coli Po2 + Eugenol (b), E. coli Po3 + MHB, E. coli Po3 + Eugenol (c), E. coli Go3 + MHB, E. coli Go3 + Eugenol (d), E. coli Go4 + MHB, E. coli Go4 + Eugenol (e), E. coli Bo+MHB, E. coli Bo + Eugenol (f). All data were expressed as mean \pm S.D., $n=3$. ${ }^{* *} P<0.01,{ }^{*} P<0.05$ vs. non-synergy group

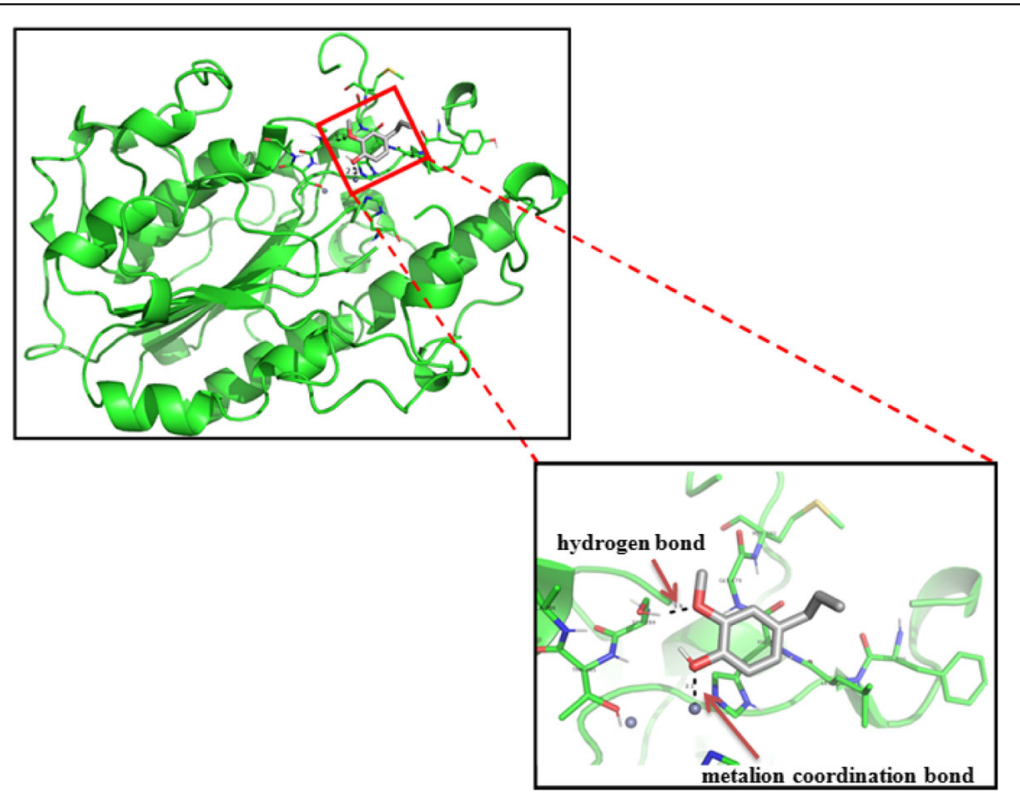

Fig. 3 Putative pattern of interaction between eugenol and MCR-1 protein. The structure eugenol was shown in gray, the green stick around eugenol are amino acid residue. Carbon atoms were shown in gray, hydrogen atoms in white, oxygen atoms in red, nitrogen atoms in blue, sulphur atoms in gamboges 
slow down the pace of multi-drug resistance is very essential.

According to many alternatives studied, EOs, with various antimicrobial characteristics, has received significant attention. EOs, as well as their components, has been explored as a source of new antimicrobials on a limited basis. Many EOs were reported to possess significant antimicrobial activity against a wide range of microorganisms [5-7]. Nowadays, EOs continue to be used to treat infectious disease in traditional medicine around the world [15]. Eugenol, the principal chemical ingredient of clove oil has been long known for its local anesthetic, anti-inflammatory, analgesic, antioxidant and antibacterial effects $[10,17]$. It belongs to the class of essential oils that is generally recognised as safe (GRAS) by the Food and Drug Administration [26]. Its nonspecific permeabilization to the cytoplasmic membrane has been demonstrated in various studies by effluxing potassium and ATP out of the bacterial cells [27-29]. It is thought that the hydroxyl group of eugenol can bind to and affect the properties of proteins and thereby contributing to eugenol's inhibitory effect at sub-lethal concentrations. Consistent with this, eugenol has proven to inhibit the activity of enzymes including ATPase, histidine decarboxylase, amylase, and protease. Inhibition of the ATPase can result in the destruction of energy generation needed for bacterial cell recovery, and further lead to the death of bacteria [27, 28].

In our study, for most clinical isolated E. coli strains, colistin-resistant or colistin-sensitive, eugenol exhibited a synergistic effect on 8 out of 14 cases (FICI, 0.375 to 0.5 ), while for the rest 6 strains, eugenol exerted partial synergistic effect(FICI, 0.625). In general, MIC for colistin was reduced by 4 to 8 -fold in the presence of eugenol. Therefore, we concluded that eugenol could enhance the antibacterial effects of colistin in both colistin-resistant and colistin-sensitive strains. The above results clearly demonstrated that eugenol exhibited strong antibacterial effect and synergistic activity when used alone or combined against colistin-resistant $E$. coli strains. Moreover, we speculate eugenol at a dose of $2 \mu \mathrm{g} / \mathrm{mL}$ may also exhibit a clinical effect when combined with colistin in vitro. However, though eugenol was reported to have a lower haemolytic activity comparing with some therapeutic agent, the dose required to perform in vivo still need further study $[5,30]$. In the literature, some studies reported that components with phenolic hydroxyl structures, such as eugenol and thymol are known to possess some antimicrobial activities as bactericidal or bacteriostatic agents against gram-positive and gram-negative bacteria, and their yeasts [5, 31-33]. Moreover, the relative position of hydroxyl group is also crucial for the bioactivity of these components [34].
Multiple drug resistance of $E$. coli is a kind of phenotype. While relative drug resistant genes plays a key role in dominating the phenotype. Studies have indicated that mRNA expression level could restrict degree and stability of multidrug resistance and there existed a positive correlation [35]. Results of real-time PCR clearly showed that expression of mcr-1 gene in synergy group was significantly lower than nonsynergy group, which indicated an inhibiting effect of eugenol on mcr-1 gene expression.

Molecular docking is a computational procedure used to predict noncovalent binding of macromolecules or a macromolecule (receptor) and a small molecule (ligand) efficiently, starting with their unbound structures obtained from molecular docking simulations or homology modeling. Docking aim to predict the possible bound conformations and the binding affinity. The prediction of binding of small molecules to proteins is of particular practical importance, which can benefit and be used to screen virtual libraries of drug-like molecules for further drug development [36]. An earlier study have demonstrated better antibacterial activity and predicted eugenol hydrogen bonded with catalytic and other crucial amino acid residues of ESBL proteins of pathogenic bacteria via molecular docking experiments, indicating an effective interactions between them [37]. Thus, to obtain better insight into interactions of eugenol and MCR-1 protein, molecular docking analysis was performed. The results indicated that phenolic hydroxyl group in eugenol could bind with zinc atom of MCR1 protein in the form of metal ion coordination bond, which could further elucidate phenolic hydroxyl as an important functional group. In addition, catalytic amino acid Ser284, which is in the active pocket of MCR-1 protein was found to hydrogen bond with methoxy in ortho-position of MCR-1 protein, thus stabilizing the docked structures. This is the first study to evaluate antimicrobial property of eugenol against colistin-resistant $E$. coli.

There are also several reports supports that the bioactive components like eugenol, carvacrol and thymol present in EOs could attach to the cell surface, and thereafter, penetrate to the phospholipid bilayer of the cell membrane. Their accumulation disturbs the structural integrity of cell membrane, which will detrimentally influence the cell metabolism and lead to cell death $[11,38]$. Similar mode of action was noted by other researchers. EOs, in general, act on cell membrane integrity by changing the membrane permeability which leads to leakage of electrolytes and loss of vital intracellular contents like amino acids, ATP and DNA while inhibiting the energy (ATP) generation and related enzymes leading to the 
destruction of cell [39-42]. Therefore, we speculate eugenol is likely to interfere with the entire bacterial cell and lead to a cascade of reactions, which act as an inhibitor.

However, the clear mechanism is not completely understood, additional functional studies would be needed to validate the possible antibacterial effect, MCR-1 protein binding and to evaluate their mode of action, which could contribute to the potential efficacy of eugenol to treat clinical colistin-resistant bacteria.

\section{Conclusions}

Our results revealed that eugenol exhibited an synergistic effect with colistin in vitro against a collection of clinical $E$. coli isolates. The synergistic effect might related to the interactions between eugenol and MCR-1 protein.

\section{Abbreviations}

AMP: Ampicillin; AZM: Azithromycin; CFZ: Cefazolin; CTX: Cefotaxime; DMSO: Dimethyl sulfoxide; DOX: Doxycycline; E.coli: Escherichia coli; EOs: Essential oils; FF: Florfenicol; FICl: Fractional inhibitory concentration index; FRZ: Furazolidone; GEN: Gentamicin; GRAS: Generally recognised as safe; KAN: Kanamycin; LB: Lysogeny broth; LVX: Levofloxacin; MDR: Multidrugresistance; MHA: Mueller-Hinton agar; MHB: Mueller-Hinton broth; MIC: Minimum inhibitory concentration; NEO: Neomycin; NOR: Norfloxacin; PEA: Phosphoethanolamine; STR: Streptomycin; TCY: Tetracycline; TTC: Triphenyltetrazolium chloride

\section{Acknowledgements}

We are grateful to the Jilin Provincial Key Laboratory of New Veterinary Drug Innovation Research and Development for support and Prof. HongXia Ma (Corresponding author) for constructive advice as well as other members who made contributions to this study.

\section{Funding}

This work was supported by National Key Research and Development Plan (Grant number: 2016YFD0501301), the Science and Technology

Development Plan of Jilin Province (Grant number 20170520074JH).

\section{Availability of data and materials}

Anyone interested in the full data in excel format can write to wym27149@126.com for the data.

\section{Authors' contributions}

YMW contributed to drafting and revising the manuscript; YMW, LCK participated in the design of the study and statistical analysis. JL performed the antimicrobial susceptibility test. All authors read and approved the final manuscript.

\section{Ethics approval and consent to participate}

Not applicable

\section{Consent for publication}

Not applicable

\section{Competing interests}

The authors declare that they have no competing interests.

\section{Publisher's Note}

Springer Nature remains neutral with regard to jurisdictional claims in published maps and institutional affiliations.
Received: 26 October 2017 Accepted: 12 January 2018

Published online: 29 January 2018

\section{References}

1. Liu YY, Wang Y, Walsh TR, Yi LX, Zhang R, Spencer J, Doi Y, Tian G, Dong B, Huang $X$, et al. Emergence of plasmid-mediated colistin resistance mechanism mcr-1 in animals and human beings in china: a microbiological and molecular biological study. Lancet Infect Dis. 2016;16:161-8.

2. Baron S, Bardet L, Dubourg G, Fichaux M, Rolain JM. Mcr-1 plasmidmediated colistin resistance gene detection in an enterobacter cloacae clinical isolate in france. J Glob Antimicrob Resist. 2017;10:35-6.

3. Elnahriry SS, Khalifa HO, Soliman AM, Ahmed AM, Hussein AM, Shimamoto T. Emergence of plasmid-mediated colistin resistance gene mcr-1 in a clinical escherichia coli isolate from egypt. Antimicrob Agents Chemother. 2016;60:3249-50.

4. von Wintersdorff CJ, Wolffs PF, van Niekerk JM, Beuken E, van Alphen LB, Stobberingh EE, Oude Lashof AM, Hoebe CJ, Savelkoul PH, Penders J. Detection of the plasmid-mediated colistin-resistance gene mcr-1 in faecal metagenomes of dutch travellers. J Antimicrob Chemother. 2016;71:3416-9.

5. Burt S. Essential oils: their antibacterial properties and potential applications in foods-a review. Int J Food Microbiol. 2004;94:223-53.

6. Fisher K, Phillips C. Potential antimicrobial uses of essential oils in food: is citrus the answer? Trends Food Sci Technol. 2008;19:156-64.

7. Friedman M, Henika PR, RE M. Bactericidal activities of plant essential oils and some of their isolated constituents against campylobacter jejuni, escherichia coli, listeria monocytogenes, and salmonella enterica. J Food Prot. 2002;65:1545-60.

8. Bajpai VK, Baek KH, Kang SC. Control of salmonella in foods by using essential oils: a review. Food Res Int. 2012;45:722-34.

9. Solórzano-Santos F, Miranda-Novales MG. Essential oils from aromatic herbs as antimicrobial agents. Curr Opin Biotechnol. 2012;23:136-41.

10. Rs P, Zhou F, Ji B, Xu J. Evaluation of combined antibacterial effects of eugenol, cinnamaldehyde, thymol, and carvacrol against e. Coli with an improved method. J Food Sci. 2009;74:M379-83.

11. Lv F, Liang H, Yuan Q, Li C. In vitro antimicrobial effects and mechanism of action of selected plant essential oil combinations against four food-related microorganisms. Food Res Int. 2011:44:3057-64.

12. Fadli M, Bolla JM, Mezrioui NE, Pagès JM, Hassani L. First evidence of antibacterial and synergistic effects of thymus riatarum essential oil with conventional antibiotics. Ind Crop Prod. 2014;61:370-6.

13. Garcia-Garcia R, Lopez-Malo A, Palou E. Bactericidal action of binary and ternary mixtures of carvacrol, thymol, and eugenol against listeria innocua. J Food Sci. 2011;76:M95-100.

14. Rai M, Paralikar P, Jogee P, Agarkar G, Ingle AP, Derita M, Zacchino S. Synergistic antimicrobial potential of essential oils in combination with nanoparticles: emerging trends and future perspectives. Int J Pharm. 2017; 519:67-78.

15. Calo JR, Crandall PG, O'Bryan CA, Ricke SC. Essential oils as antimicrobials in food systems - a review. Food Control. 2015;54:111-9.

16. de Souza TB, POB R, Andrade SF, TMM H, Silva NC, ALT D, Ikegaki M, Rocha RP, LFL C, Veloso MP, et al. synthesis and antimicrobial activity of 6-triazolo6-deoxy eugenol glucosides. Carbohydr Res. 2015;410:1-8.

17. Miladi H, Zmantar T, Kouidhi B, Chaabouni Y, Mahdouani K, Bakhrouf A, Chaieb K. Use of carvacrol, thymol, and eugenol for biofilm eradication and resistance modifying susceptibility of salmonella enterica serovar typhimurium strains to nalidixic acid. Microb Pathog. 2017;104:56-63.

18. Andrews JM. Determination Of minimum inhibitory concentrations. J Antimicrob Chemother. 2001:48(Suppl 1):5-16.

19. Draper LA, Cotter PD, Hill C, Ross RP. The two peptide lantibiotic lacticin 3147 acts synergistically with polymyxin to inhibit gram negative bacteria. BMC Microbiol. 2013;13:212.

20. Rice LB. Challenges in identifying new antimicrobial agents effective for treating infections with acinetobacter baumannii and pseudomonas aeruginosa. Clin Infect Dis 2006; $43 \backslash 2$ : S100-S105.

21. Li J, Nation RL, Owen RJ, Wong S, Spelman D, Franklin C. Antibiograms of multidrug-resistant clinical acinetobacter baumannii: promising therapeutic options for treatment of infection with colistin-resistant strains. Clin Infect Dis. 2007;45:594-8.

22. Xavier BB, Lammens $C$, Ruhal R, Kumar-Singh S, Butaye $P$, Goossens $H$, Malhotra-Kumar S. Identification of a novel plasmid-mediated colistin- 
resistance gene, mcr-2, in escherichia coli, belgium, june 2016. Euro Surveill. 2016;21

23. Ma G, Zhu Y, Yu Z, Ahmad A, Zhang H. High resolution crystal structure of the catalytic domain of mcr-1. Sci Rep. 2016;6(39540)

24. Wanty C, Anandan A, Piek S, Walshe J, Ganguly J, Carlson RW, Stubbs KA, Kahler CM, Vrielink $A$. The structure of the neisserial lipooligosaccharide phosphoethanolamine transferase a (lpta) required for resistance to polymyxin. J Mol Biol. 2013;425:3389-402.

25. Fage CD, Brown DB, Boll JM, Keatinge-Clay AT, Trent MS. Crystallographic study of the phosphoethanolamine transferase eptc required for polymyxin resistance and motility in campylobacter jejuni. Acta Crystallogr D Biol Crystallogr. 2014;70:2730-9.

26. Hemaiswarya S, Doble M. Synergistic interaction of eugenol with antibiotics against gram negative bacteria. Phytomedicine. 2009;16:997-1005.

27. Hyldgaard M, Mygind T, Meyer RL. Essential oils in food preservation: mode of action, synergies, and interactions with food matrix components. Front Microbiol. 2012;3(12)

28. Gill AO, Holley RA. Inhibition of membrane bound atpases of escherichia coli and listeria monocytogenes by plant oil aromatics. Int J Food Microbiol. 2006;111:170-4.

29. Gill AO, Holley RA. Disruption Of escherichia coli, listeria monocytogenes and lactobacillus sakei cellular membranes by plant oil aromatics. Int J Food Microbiol. 2006;108:1-9.

30. Adil M, Singh K, Verma PK, Khan AU. Eugenol-induced suppression of biofilm-forming genes in streptococcus mutans: an approach to inhibit biofilms. J Glob Antimicrob Resist. 2014;2:286-92.

31. Lebert I, Leroy S, Talon R. Effect of industrial and natural biocides on spoilage, pathogenic and technological strains grown in biofilm. Food Microbiol. 2007;24:281-7.

32. Dorman HJ, Deans SG. Antimicrobial agents from plants: antibacterial activity of plant volatile oils. J Appl Microbiol. 2000;88:308-16.

33. Mayaud L, Carricajo A, Zhiri A, Aubert G. Comparison of bacteriostatic and bactericidal activity of 13 essential oils against strains with varying sensitivity to antibiotics. Lett Appl Microbiol. 2008;47:167-73.

34. Veldhuizen EJ, Tjeerdsma-van Bokhoven JL, Zweijtzer C, Burt SA, Haagsman HP. Structural requirements for the antimicrobial activity of carvacrol. J Agric Food Chem. 2006:54:1874-9.

35. Baylay AJ, Ivens A, Piddock LJV. A novel gene amplification causes upregulation of the patab abc transporter and fluoroquinolone resistance in streptococcus pneumoniae. Antimicrob Agents Chemother. 2015;59:3098-108

36. Trott O, Olson AJ. Autodock Vina: improving the speed and accuracy of docking with a new scoring function, efficient optimization, and multithreading. J Comput Chem. 2010;31:455-61.

37. Dhara L, Tripathi A. Antimicrobial activity of eugenol and cinnamaldehyde against extended spectrum beta lactamase producing enterobacteriaceae by in vitro and molecular docking analysis. European Journal of Integrative Medicine. 2013:5:527-36.

38. Bajpai VK, Sharma A, Baek KH. Antibacterial mode of action of cudrania tricuspidata fruit essential oil, affecting membrane permeability and surface characteristics of food-borne pathogens. Food Control. 2013;32:582-90.

39. Cui H, Zhang X, Zhou H, Zhao C, Lin L. Antimicrobial activity and mechanisms of salvia sclarea essential oil. Bot Stud. 2015;56

40. Huang DF, Xu JG, Liu JX, Zhang H, Hu QP. Chemical constituents, antibacterial activity and mechanism of action of the essential oil from cinnamomum cassia bark against four food-related bacteria. Microbiology. 2014:83:357-65.

41. Li CM, Yu JP. Chemical composition, antimicrobial activity and mechanism of action of essential oil from the leaves ofmacleaya cordata(willd.) r. Br. J Food Saf. 2015;35:227-36.

42. Skočibušić M, Bezić N, Dunkić V. Phytochemical composition and antimicrobial activities of the essential oils from satureja subspicata vis Growing in croatia. Food Chem. 2006;96:20-8.

\section{Submit your next manuscript to BioMed Central and we will help you at every step:}

- We accept pre-submission inquiries

- Our selector tool helps you to find the most relevant journal

- We provide round the clock customer support

- Convenient online submission

- Thorough peer review

- Inclusion in PubMed and all major indexing services

- Maximum visibility for your research

Submit your manuscript at www.biomedcentral.com/submit
Biomed Central 